\title{
Ensuring the Competitiveness of the Ukrainian Woodworking Industry in the Post-Pandemic Period
}

\author{
Irina Hubarieva ${ }^{*}$, Oleksandr Hubariev ${ }^{2}$,Volodymyr Zinchenko ${ }^{3}$, and Pavlo Pronoza ${ }^{4}$ \\ ${ }^{1}$ National Academy of Sciences of Ukraine, Research Centre for Industrial Problems of \\ Development, 1a Inzhenernyi Ln., Kharkiv, 61166, Ukraine \\ ${ }^{2}$ Kharkiv State Academy of Culture, 4 Bursatskyi Des., Kharkiv, 61057, Ukraine \\ ${ }^{3}$ National Academy of Sciences of Ukraine, Research Centre for Industrial Problems of Development, \\ 1a Inzhenernyi Ln., Kharkiv, 61166, Ukraine \\ ${ }^{4}$ Simon Kuznets Kharkiv National University of Economics, Nauky avenue, 9-A, Kharkiv, 61166, \\ Ukraine
}

\begin{abstract}
The woodworking industry is one of the most critical components of the forest sector in Ukraine and world countries. This paper aims to develop directions for ensuring the competitiveness of the woodworking industry in the post-pandemic period. The study resulted in the elaboration of the theoretical framework for identifying the main substantive determinants of industrial competitiveness in world countries through bibliometric analysis using VOSviewer v.1.6.10. The conducted cluster analysis provided for the identification of 4 clusters of scientific research dealing with issues of industrial competitiveness (Cluster 1 is focused on the formation of a competitive business strategy for the development of industrial enterprises; Cluster 2 - on the development of the export-import potential of industrial enterprises; Cluster 3 - on the identification of relationships between ensuring industrial competitiveness and globalisation processes; Cluster 4 - on the implementation of Industry 4.0 and innovative technologies). The obtained theoretical conclusions and generalisations became the basis for forming a system of indicators for assessing the competitiveness of economic activities in the country's woodworking industry. An integrated assessment of the competitiveness of the woodworking industry in Ukraine and world countries was carried out. Using cluster analysis (k-means), world countries, including Ukraine, were clustered according to the value of composite indicators for assessing the competitiveness of individual economic activities in the woodworking industry. Ukraine fell into the cluster characterised by the high competitiveness of individual economic activities in the woodworking industry. Measures were formulated to ensure the competitiveness of the Ukrainian woodworking industry in the post-pandemic period. Keywords: competitiveness, woodworking industry, a composite indicator, cluster analysis, bibliometric analysis, post-pandemic period
\end{abstract}

* Corresponding author: gubarievairyna@gmail.com 


\section{Introduction}

The COVID-19 pandemic has affected the lives and health of people and the movement of goods, labour, consumption, transportation, and distribution of resources. The problem of ensuring the competitiveness of the industrial sector is becoming increasingly pressing in the post-pandemic period. The woodworking industry is one of the essential components of the forest sector in Ukraine and world countries: it includes enterprises engaged in mechanical and chemomechanical pulping, wood processing and is a critical element of the technological chain: forest cultivation-logging-processing-manufacturing of final products.

The competitiveness of the industrial sector forms the competitiveness of the national economy. The woodworking industry of any country across the world includes economic activities that differ in terms of complexity of production technologies, gross value added, and efficiency both for the country's economy as a whole and individual business entities.

\section{Analysis of current research of the problem}

The urgency of ensuring the competitiveness of objects at different levels of the hierarchy is evidenced by the frequency of citation of publications in this field in the Scopus scientometric database. The top five most cited publications on the problem of competitiveness, indexed in the Scopus database during 1990-2021, includes the following works: D. Teece (2007) [1] - 5050 citations, M. Porter (2000) [2] - 2236 citations, P. Bansal, K. Roth (2000) [3] - 1931 citations, M. Porter (1991) [4] - 1786 citations, J. Jansen et al. (2006) [5] - 1656 citations.

"Competitiveness is one of the main categories widely used in the theory and practice of economic sciences, a multi-faceted concept translated from Latin as rivalry, struggle to achieve the best results" [6].

In a global economy, competitiveness can be defined as the ability of the country's industrial sector to meet international competition in its market and markets of other countries. Therefore, it is relevant to develop analytical tools for assessing the level of competitiveness of industries in Ukraine and world countries.

The problem of ensuring industrial competitiveness has attracted the attention of theorists and practitioners for a long time. This study aims to systematise and generalise the existing scientific publications, indexed in the Scopus and Web of Science scientometric databases, on the competitiveness of the industry as a whole and the competitiveness of the woodworking industry in particular.

The preliminary analysis of scientific publications on industrial competitiveness, indexed in Scopus and Web of Science, showed that the oldest Scopus indexed article on this issue is the work by R. Stuchtler (1967) [7], which is focused on the investigation of the competitiveness of the German metallurgical industry. The oldest article on the competitiveness of the woodworking industry is the work by V. Carlsson, L. Ohlsson (1976) [8], which identifies the structural determinants of Sweden's export competitiveness: the availability of domestic timber in combination with high capital intensity and investment in the woodworking industry.

However, one of the latest publications on industrial competitiveness is F. Suarez et al. (2022) [9], where scientists note the need to use clustering to ensure the textile industry's competitiveness in the post-pandemic era. One of the most recent publications on the competitiveness of the woodworking industry is the article by S. Krišt'Aková et al. (2018) [10], which deals with assessing the efficiency of woodworking enterprises in Slovakia and Bulgaria.

Among the publications indexed in Web of Science, the oldest document on the problem of industrial competitiveness is the article by CS Giesecke [11] (1972), where the author investigates costs associated with competitiveness in the Swedish industry; and the oldest 
document on the problem of competitiveness of the woodworking industry is the article by H. Kato (1974) [12], which deals with the assessment of the competitiveness of woodworking machines.

One of the recent publications on industrial competitiveness, indexed in Web of Science, is the article by L. Gastaldi et al. (2022) [13], which deals with studying the consequences of the industry's transition to Industry 4.0. One of the recent publications on the problem of competitiveness of the woodworking industry is that by J. Michal et al. (2021) [14], which proposes a model for sustainable development of woodworking enterprises in the Czech Republic.

To identify the contextual and temporal patterns of the representation of research on industrial competitiveness in the scientific literature, a bibliometric analysis of scientific publications indexed in the Scopus and Web of Sciences databases was carried out using VOSviewer v. 1.6.10 [15].

In the study, 24183 scientific publications indexed in Scopus and 29903 indexed in Web of Science for the period 1971-2021 were analysed. The search was performed using the keywords "competitiveness, industry".

Considering the results of the bibliometric analysis, we can single out 4 contextual clusters of research dealing with industrial competitiveness, which include the most significant number of publications: Cluster 1, which contains publications that consider enterprise competitiveness (the main keywords: business, competitive advantages, product, resources, strategy, management); Cluster 2, which is formed by works focused on identifying bilateral relationships between industrial competitiveness and market determinants (main keywords: export, market size, monopoly, protectionism, taxes); Cluster 3 , includes publications that deal with revealing the impact of globalisation processes, introduction of innovations, increase in labor productivity and level of qualification of workers, infrastructure development on industrial competitiveness; Cluster 4, covers articles on industrial competitiveness in the context of government regulation, industrial policy, clusters, technological development, Industry 4.0.

\section{Key issues and hypothesis of the research}

Given the conducted analysis of publications considering problems of ensuring industrial competitiveness, in our opinion, further research is required on several issues, in particular:

- how the level of competitiveness of individual economic activities affects the level of competitiveness of the country's woodworking industry;

- what patterns of development of the woodworking industry can be distinguished in the clusters formed by world countries;

- what the directions for ensuring the competitiveness of the woodworking industry in the post-pandemic period are.

This study presents an attempt to solve these problems; its central hypothesis is formulated as follows: ensuring the competitiveness of the Ukrainian woodworking industry in the post-pandemic period depends on the development of the economic activities in the woodworking industry that are export-oriented and have the most negligible dependence of intermediate production on imports.

\section{Materials and Methods}

The research aims to develop directions for ensuring the competitiveness of the woodworking industry in the post-pandemic period. 
The object of the research is the competitiveness of the woodworking industry in world countries and Ukraine.

To achieve the set goals, the following research objectives are set:

1. to elaborate a theoretical framework for assessing and analysing the level of industrial competitiveness in world countries;

2. to assess the level of competitiveness of individual economic activities in the woodworking industry in world countries and Ukraine (using the composite indicator);

3. to carry out the clustering of world countries and Ukraine according to the level of competitiveness of the woodworking industry and identify groups of countries that are homogeneous in the level and are characterised by similar patterns of development;

4. to identify ways for ensuring the competitiveness of the woodworking industry in the post-pandemic period.

The primary sample of research on competitiveness of economic activities in the woodworking industry in world countries comprises data of analytical reports on the world's forest resources of the Food and Agriculture Organization of the United Nations (FAO) and the United Nations Economic Commission for Europe (ECE) [16-24].

Given the tasks set, the study employs the following methods:

1. general scientific methods: analysis and synthesis, generalisation, and bibliometric analysis, to elaborate the theoretical framework for ensuring and assessing the competitiveness of the woodworking industry;

2. the method for calculating the composite indicator, to assess the competitiveness of economic activities in the woodworking industry in world countries and Ukraine;

3. cluster analysis, to cluster world countries and Ukraine by the level of competitiveness of the woodworking industry.

Thus, the study consists of three main parts.

The first one deals with elaborating the theoretical framework of the study. It involves the analysis of research works on the issues under study and is aimed at the substantiation, on this basis, of approaches to ensuring and assessing the competitiveness of the country's woodworking industry.

The second part focuses on calculating the composite indicator of the competitiveness of economic activities in the country's woodworking industry. As a basis for assessing the competitiveness of economic activities in the country's woodworking industry, it is proposed to put a hierarchically built system of indicators, including the composite indicator and subindicators (grouped by corresponding components). The composite indicator is compiled using the taxonomy method, which makes it possible to determine the level of and disproportions in the development of the country's woodworking industry and can serve as a basis for the formation of directions for increasing its competitiveness.

The third part of the study deals with clustering world countries according to the level of competitiveness of economic activities in the woodworking industry and determining ways to ensure the competitiveness of the woodworking industry in Ukraine in the post-pandemic period. The primary research method used for this purpose is cluster analysis.

Clustering is the most common tool for object typology. It implies classifying objects (in our study, countries) into relatively homogeneous groups, considering the considered number of features (indicators, variables). Cluster analysis methods are covered in sufficient detail in many scientific works and are widely used in economic research. When clustering countries by level of competitiveness of the woodworking industry, the Euclidean distance was chosen to measure the distance between objects, and the Ward principle - to measure the distance between clusters. The result of applying cluster analysis in the framework of this study should be the identification of groups of countries that are homogeneous in terms of competitiveness of the woodworking industry and have similar patterns of development. 


\section{Results}

Summarising the results of the study of the modern scientific literature, the main substantive determinants of competitiveness of the country's industry were identified through bibliometric analysis using VOSviewer v.1.6.10. The formalisation of contextual features of the studied concept is based on the bibliometric analysis results of 24183 scientific publications indexed in the Scopus scientometric database and 29903 ones indexed in Web of Science for the period 1971-2021, was carried out. This made it possible to find out that analysis of relationships between the competitiveness of the industry and an enhancement in the efficiency and sustainable development of industrial enterprises, introduction of innovative technologies, greening of production is becoming increasingly popular.

Thus, we identified four clusters of scientific research dealing with issues of industrial competitiveness (Cluster 1 is focused on the formation of a competitive business strategy for the development of industrial enterprises; Cluster 2 - on the development of the exportimport potential of industrial enterprises; Cluster 3 - on the identification of relationships between ensuring industrial competitiveness and globalisation processes; Cluster 4 - on the implementation of Industry 4.0 and innovative technologies). The obtained theoretical conclusions and generalisations provided the basis for forming a system of indicators for assessing the competitiveness of economic activities in the country's woodworking industry.

Industry of any country across the world includes economic activities that differ in terms of complexity of production technologies, gross value-added, and efficiency both for the country's economy as a whole and individual business entities.

The manufacturing of wood and wood products is divided into the preparation and primary processing of wood and secondary wood. Preparation and primary processing of wood include the following: production of veneer, pulp chips and timber (planks, beams, rough-sawn timber). Secondary processing involves the following: production of plywood, boards (chipboard, fiberboard, MDF, OSB, etc.), trim mouldings, laminated wood beams and bars, laminated wood constructions $[25 ; 26]$.

The study shows that the level of development and efficiency of the country's woodworking industry is determined by three economic activities: timber production, veneer production, and board materials.

Let us assess the competitiveness of individual economic activities in the woodworking industry in Ukraine and world countries.

Based on the results of the bibliometric analysis and data of the annual analytical reports on the world's forest resources of the Food and Agriculture Organization of the United Nations (FAO) and the United Nations Economic Commission for Europe (ECE) [7-16], the following system of sub-indicators is proposed to assess the competitiveness of economic activities in the woodworking industry (Tbl. 1).

It is proposed to carry out an integrated assessment of the competitiveness of economic activities in the country's woodworking industry ( $\left.\mathrm{I}_{\mathrm{WI}}\right)$ using the formula:

$$
\mathrm{I}_{\mathrm{WI}}=\sum_{z=1}^{3} \mathrm{a}_{z} \mathrm{~K}_{\mathrm{zj}}
$$

where $a_{z}$ is the coefficient of variation of the composite indicator for assessing the competitiveness of the z-th economic activity in the woodworking industry;

3 is the number of economic activities in the country's woodworking industry;

$C_{z j}$ is the composite indicator for assessing the competitiveness of the z-th type of economic activity in the wood-processing industry in the $\mathrm{j}$-th country, calculated by the formula:

$$
C_{\mathrm{zj}}=\sum_{l=1}^{3} ß_{l z} \mathrm{X}_{l \mathrm{z}_{j}}
$$


where $\beta_{l z}$ is the coefficient of variation of the $l$-th sub-indicator for assessing the competitiveness of the $\mathrm{z}$-th economic activity in the country's woodworking industry;

$X_{l z_{j}}$ is the $l$-th sub-indicator for assessing the competitiveness of the $\mathrm{z}$-th economic activity in the woodworking industry;

3 is the number of sub-indicators for assessing the competitiveness of individual economic activity in the country's woodworking industry.

Table 1. The system of sub-indicators for assessing the competitiveness of economic activities in the country's woodworking industry

\begin{tabular}{|l|l|}
\hline \multicolumn{1}{|c|}{ Sub-indicator } & \multicolumn{1}{|c|}{ Calculation formula } \\
\hline $\begin{array}{l}\text { The share of production of } \\
\text { economic activities in the } \\
\text { overall production of the } \\
\text { woodworking industry }\end{array}$ & $\begin{array}{l}\text { Where } V_{i} \text { is the volume of production of economic activities in the } \\
\text { woodworking industry; } V_{W I} \text { is the overall production of the } \\
\text { woodworking industry }\end{array}$ \\
\hline $\begin{array}{l}\text { The share of exports in the } \\
\text { volume of production of } \\
\text { economic activities in the } \\
\text { woodworking industry }\end{array}$ & $\begin{array}{l}\text { where } E_{i} \text { is the volume of exports of economic activities in the } \\
\text { woodworking industry }\end{array}$ \\
\hline $\begin{array}{l}\text { Import dependence of the } \\
\text { economic activities in the } \\
\text { woodworking industry }\end{array}$ & $\begin{array}{l}\text { Where } \mathrm{I}_{i} \text { is the volume of imports of economic activities in the } \\
\text { woodworking industry; } D_{i} \text { is the volume of domestic consumption of } \\
\text { economic activities in the woodworking industry }\end{array}$ \\
\hline
\end{tabular}

Figure 2 presents a diagram of the distribution of Ukraine and world countries according to the composite indicator for assessing the competitiveness of economic activities in the woodworking industry in 2019.

As can be seen from Figure 1, the leading countries in terms of competitiveness of economic activities in the woodworking industry in 2019 are Latvia (0.4906), Austria (0.4255), Ukraine (0.4144), Russia (0.4096), and Estonia (0.3969).

The group of countries with a low level of the composite indicator for assessing the competitiveness of economic activities in the woodworking industry includes Belgium (0.2724), Sweden (0.2527), Japan (0.2508), Greece (0, 2237), and Great Britain (0.2165).

Using cluster analysis (k-means), countries of the world, including Ukraine, are classified according to the value of the combined indicators for assessing the competitiveness of economic activities in the woodworking industry.

Cluster 1, which is characterised by a high level of competitiveness of individual economic activities in the woodworking industry, comprises fifteen countries, namely: Austria, Brazil, Denmark, Estonia, Canada, Latvia, Lithuania, Mexico, Portugal, Russia, Romania, Hungary, Finland, the Czech Republic, and Ukraine.

Cluster 2, characterised by a low level of competitiveness of individual economic activities in the woodworking industry, is formed by 21 countries: Australia, Belgium, Bulgaria, Great Britain, Greece, India, Ireland, Spain, Italy, China, Korea, Netherlands, Germany, Poland, Slovakia, Slovenia, USA, Turkey, France, Sweden, and Japan.

The conducted analysis has made it possible to recommend the countries that belong to the 1st cluster (including Ukraine), characterised by a high level of competitiveness of economic activities in the woodworking industry, to focus on increasing the export of high value-added wood products, such as board materials. 


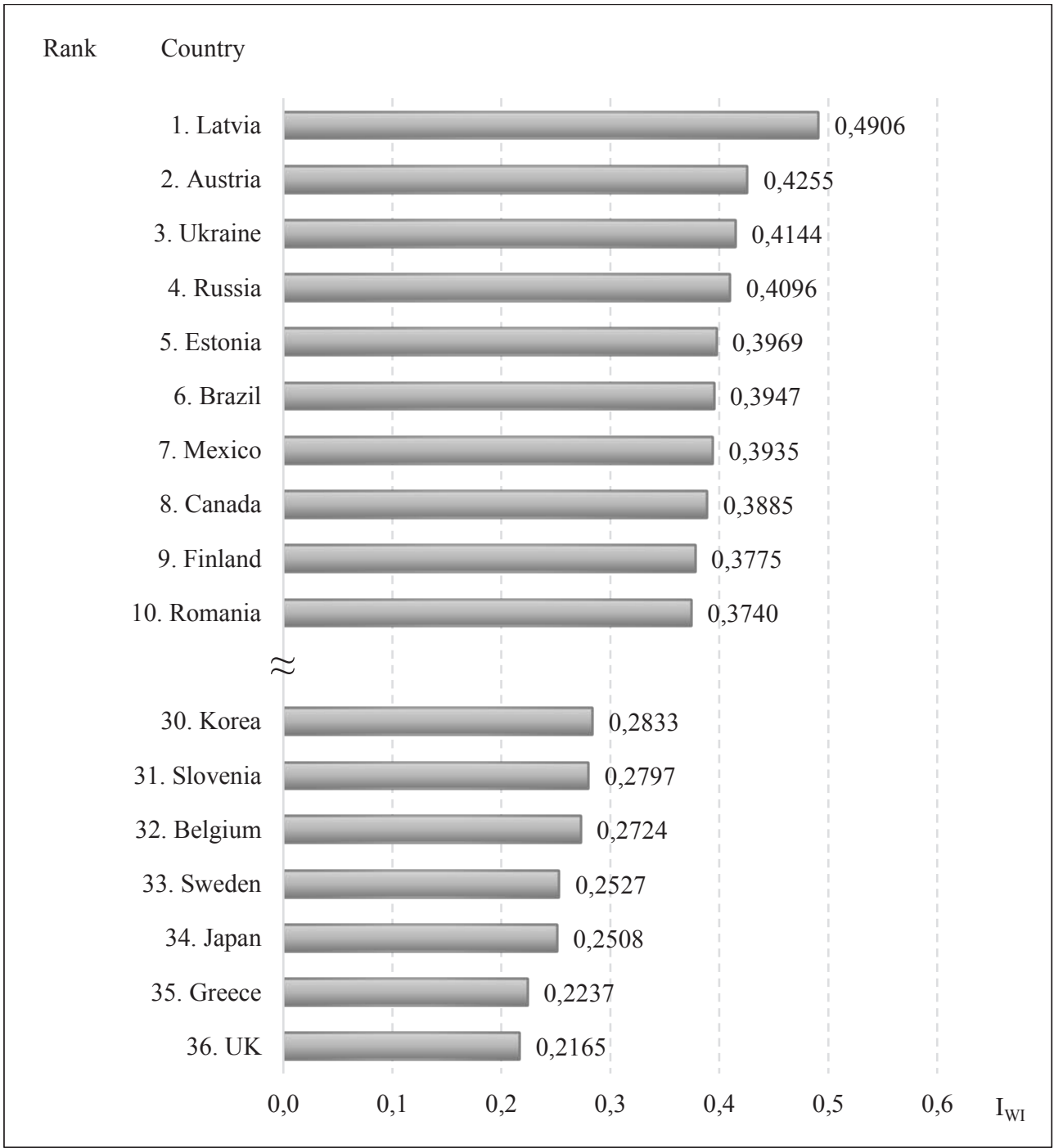

Fig 1. Diagram of the distribution of Ukraine and world countries according to the composite indicator for assessing the competitiveness of economic activities in the woodworking industry in 2019 (developed by the authors)

The clustering of the studied countries by individual economic activities in the woodworking industry demonstrates that Ukraine predominantly falls into the cluster characterised by a high share of production of the economic activities and low values of the share of exports and import dependence of the sub-indicators for assessing the competitiveness of economic activities in the woodworking industry.

In the post-pandemic period, the issues of creating conditions for preventing and minimising economic losses and recession in the industrial sector of Ukraine are becoming aggravated.

During the COVID-19 pandemic, in Ukraine, enterprises in various industries temporarily, fully or partially ceased their operation, which was due to imposing strict quarantine rules, a decrease in the demand for non-essential goods, the introduction of restrictions on Ukrainian products in the markets of world countries, etc. This resulted in the loss of income, potential loss of specialists by these entities and even their bankruptcy. 
State support for woodworking enterprises in the post-pandemic period should include the following measures: developing strategic directions for the growth of the woodworking industry; relieving the tax and administrative pressure; decreasing the share of the shadow economy in the forest sector by providing incentives for the holding of timber tenders via the Prozoro electronic procurement system; under the deteriorating conditions in foreign markets, it is crucial to stimulate industrial production by increasing domestic demand through government procurement and protection of local producers.

The measures to ensure the competitiveness of the woodworking industry in Ukraine in the post-pandemic period also include: enhancing secondary processing by reorienting the industry towards manufacturing higher value-added products (e.g., boards), with the focus on increasing sales in the domestic and foreign markets; stimulating the design and construction of infrastructure and industrial parks to attract investment; implementing the ecological modernisation of enterprises; encouraging the use of digital innovation; expanding e-commerce.

\section{Conclusions and Discussion}

Thus, the study has provided for formulating the following main conclusions and ideas:

1. As a result of the study, the theoretical framework for identifying the main substantive determinants of industrial competitiveness in world countries has been elaborated (through bibliometric analysis with the use of VOSviewer v.1.6.10). The formalisation of contextual features of the studied concept is based on the bibliometric analysis results of 24183 scientific publications indexed in the Scopus scientometric database and 29903 ones indexed in Web of Science for the period 1971-2021, was carried out. This made it possible to find out that analysis of relationships between the competitiveness of the industry and an enhancement in the efficiency and sustainable development of industrial enterprises, introduction of innovative technologies, greening of production is becoming increasingly popular. Thus, we identified 4 clusters of scientific research dealing with issues of industrial competitiveness (Cluster 1 is focused on the formation of a competitive business strategy for the development of industrial enterprises; Cluster 2 - on the development of the export-import potential of industrial enterprises; Cluster 3 - on the identification of relationships between ensuring industrial competitiveness and globalisation processes; Cluster 4 - on the implementation of Industry 4.0 and innovative technologies). The obtained theoretical conclusions and generalisations provided the basis for forming a system of indicators for assessing the competitiveness of economic activities in the country's woodworking industry.

2. An integrated assessment of the competitiveness of individual economic activities in the woodworking industry in Ukraine and world countries has been carried out. It is determined that the leading countries in terms of the competitiveness of the woodworking industry in the considered period are: Latvia (0.4906), Austria (0.4255), Ukraine (0.4144), Russia (0.4096) and Estonia (0.3969). The group of world countries with a low level of the composite indicator for assessing the competitiveness of the woodworking industry includes Belgium (0.2724), Sweden (0.2527), Japan (0.2508), Greece (0.2237), and the UK (0.2165).

3. Using cluster analysis (k-means), world countries, including Ukraine, have been classified according to the value of the composite indicators for assessing the competitiveness of individual economic activities in the woodworking industry.

Cluster 1, characterised by a high level of competitiveness of individual economic activities in the woodworking industry, includes fifteen countries of the world, namely: Austria, Brazil, Denmark, Estonia, Canada, Latvia, Lithuania, Mexico, Portugal, Russia, Romania, Hungary, Finland, the Czech Republic, and Ukraine. Cluster 2, characterised by a low level of competitiveness of individual economic activities in the woodworking industry, comprises 21 countries: Australia, Belgium, Bulgaria, Great Britain, Greece, India, Ireland, 
Spain, Italy, China, Korea, Netherlands, Germany, Poland, Slovakia, Slovenia, the USA, Turkey, France, Sweden, and Japan.

4. It has been established that a similar situation is observed with the competitiveness of individual economic activities in the Ukrainian woodworking industry. The clustering of the studied countries demonstrates that Ukraine predominantly falls into the cluster characterised by a high share of production of the economic activities and low values of the share of exports and import dependence of the sub-indicators for assessing the competitiveness of economic activities in the woodworking industry.

5. The methodological approach to assessing the competitiveness of economic activities in the country's woodworking industry has been proposed. The approach considers the scale of production, export orientation, and dependence of intermediate production on imports, making it possible to determine the priority directions for the development of the Ukrainian woodworking industry in the post-pandemic period.

6. Measures to ensure the competitiveness of the woodworking industry in the postpandemic period have been formulated.

\section{References}

1. D.J. Teece Strategic Manage J. 28 (2007)

2. M.E. Porter Econ. Dev. Q. 14 (2000)

3. P. Bansal, K. Roth, Acad. Manage J. 43 (2000)

4. M.E. Porter Strategic Manage J. 12 (1991)

5. J.J.P. Jansen, F.A.J Van Den Bosch, H.W. Volberda, Manage Sci. 52 (2006)

6. S.M. Klimenko, T.V. Omelyanenko, D.O. Barabas and others. Enterprise competitiveness management (2008)

7. R. Stuchtey R. Inter. Econ. 2 (1967)

8. B. Carlsson, L. Ohlsson. Eur. Econom. Rev. 7 (1976)

9. F.R.L. Suárez, O. Flor, C. Chimbo C. Smart Innov. Syst. Technol. 252 (2021)

10. S. Krišt'Aková, N. Neykov, P. Antov, M. Sedliačiková, R. Reh, A.-F. Halalisan, I. Hajdúchová. Forests. 12 (2021)

11. CS. Giesecke. Jernkontoret. ANN. 156 (1972)

12. H. Kato. Bus. Japan. 19 (1974)

13. L. Gastaldi, S. Lessanibahri, G. Tedaldi, G. Miragliotta Technol. Forecast. Soc. $174(2021)$

14. J. Michal, D. Brezina, D. Safarik, R. Baduka. Forests. 12 (2021)

15. VOSviewer

16. Forest Products Annual Market Review 2019-2020 (2021)

17. Yearbook of forest products 2019 / FAO (2021).

18. Global Forest Resources Assessments. Country Reports 2020 (2021)

19. Forest Products Annual Market Review 2018-2019 (2020)

20. Forestry Production and Trade (2021)

21. The Global Forest Resources Assessments (2020)

22. The State of the World's Forests (2020)

23. Forest Products Annual Market Review 2018-2019 / Food and Agriculture Organization of the United Nations (2020)

24. Forest Products Annual Market Review 2017-2018 / Food and Agriculture Organization of the United Nations (2019)

25. M. Kyzym, I. Yaroshenko, V. Khaustova, I. Hubarieva I. Formation of strategic priorities for the development of the timber industry complex of Ukraine (2019) 
26. I. Gryshova, M. Kyzym, V. Khaustova, V. Korneev, H. Kramarev. Sustainability 12 (2020) 